\title{
Recovery of Monomer from Nylon Waste powder for its Recycling
}

\section{DILIP B. PATIL ${ }^{1}$ and SWAPNIL V.MADHAMSHETTIWAR ${ }^{2}$}

\author{
${ }^{1}$ Department of Chemistry, Institute of Science, Nagpur - 440 001, India. \\ 2Department of Chemistry, Sardar Patel Mahavidyalaya, Chandrapur - 442 402, India.
}

http://dx.doi.org/10.13005/ojc/300113

(Received: December 25, 2014; Accepted: January 14, 2014)

\begin{abstract}
Recovery of monomer hexamethylene diamine(HMD) in the form of dibenzoyl derivative of hexamethylene diamine (DBHMD) from Nylon waste rope powder was carried out by degradation of Nylon waste powder of nylon rope waste. The molecular weight of nylon waste powder was found to be 26582. The minimum amount of nylon waste powder and hydrochloric acid required for maximum recovery of $\mathrm{HMD}$ and $\mathrm{DBHMD}$ was found to be $3 \mathrm{~g}$ and $5 \mathrm{~N}, 50 \mathrm{ml}$ hydrochloric acid respectively. Further it was observed that the maximum time and temperature required for getting maximum yield of DBHMD was 120 minutes and $80^{\circ} \mathrm{C}$ respectively.
\end{abstract}

Key words: Nylon waste,Depolymerisation,recovery of monomer, Hydrolysis, Hexamethylene diamine (HMD),DBHMD.

\section{INTRODUCTION}

Every year thousand tons of polymers are produced in the country and it has been estimated that over $25 \%$ of this produce ends up in the municipal disposal sites every year. Nylon account for less that $5 \%$ of all solid waste, but the value of this scrap represent large percentage of total value of all Solid wastes. There are two ways by which this solid waste is generated.

i) Large amount of post-used nylon rope and carpet are discarded every year. This waste is disposed of by land filling while small portion is incinerated. This nylon fiber are mainly comprises of Nylon-6 and Nylon 66. ii) During the production of Nylon fiber ${ }^{1}$ the waste is generated.

The waste generated mainly of two types ${ }^{2}$, one is aqueous extractable ${ }^{3}$ and second is Solid Waste ${ }^{4}$. Now a day's all industries are engaged in developing recycling process to overcome financial burden and environmental constraints. Chemical recycling of waste polymer has attracted great attention in recent years as a means of obtaining valuable products ${ }^{5-6}$. There are three ways of chemical recycling of nylon waste powder. The first way is Depolymerisation of polymer into their constituent monomer like Caprolactum, hexamethylene diamine and adipic acid ${ }^{6}$ or other 
useful oligomers. The second alternative is the use of Solvent for the extraction of polymer and third way of recycling is to produce thermoplastic mixtures by melt blending the nylon waste. The Kinetic study of hydrothermal depolymerisation of nylon has been carried out by Tomoko et al., ${ }^{8}$ while the identification of degradation product was done by Hommez and Goethals $^{9}$. X-ray diffraction and I.R. spectroscopic investigation of the product of depolymerisation of Nylon was done by Mladeov et al.,10. In 1931, Chemist at E.I DuPont de Nemours discovered, Nylon 66 which later on became one of the most used fiber material. Nylon 66 is the polyamide formed by the condensation reaction between hexamethylene diamine and adipic acid. Each of the monomer has 6 carbon atoms hence the designation 66 . The initial applications of nylon 66 were sewing thread, Parachute fabric and women's hosiery after World War II, Nylon 66 becomes the most used artificial material with varieties of applications. By 1940s, is was already being used for upholstery and in carpet $^{11}$.

Above mentioned reasons show the considerable importance of recovery of monomer from nylon waste.

\section{EXPERIMENTAL}

\section{Material, Chemicals and Reagents}

The nylon waste in the form of nylon rope were procured and crushed into fine powder after deep freezing it to increase its brittleness similarly Nylon-66 were specially ordered for this experimental work of A.R. grade was used without further purification, in the powdered form. Hydrochloric acid used for hydrothermal depolymesisation of Nylon waste also of A.R.grade of E.Merck. Benzoyl chloride was used for recovery of hexamethylene diamine in the form of it's derivative was of A.R.grade of E.Merck. Double distilled and deionized water was used throughout the experiment. It was checked on

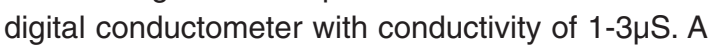
$5 \mathrm{~N}$ Stock solution of hydrochloric acid $(\mathrm{HCl})$ was prepared by diluting known volume of pure and concentrated $\mathrm{HCl}(11.3 \mathrm{~N})$ in $100 \mathrm{ml}$ volumetric flask.

\section{Determination of Molecular weight}

The average molecular weight of Nylon
-66 waste powder was determined by Ostwald's viscometer. Solvent which was used to prepare Solution of Nylon-66 was m-Cresol. Various Concentration ranging from $2 \%, 1 \%, 0.5 \%, 0.25 \%$ were prepared by dissolving Nylon-66 in m-cresol and flow time was measured. By using the equation $[\eta]=K . M^{\alpha}$ molecular weight of Nylon -66 was determined.The values of constant $\mathrm{K}$ and $\alpha$ for $\mathrm{m}$-cresol are $2.4 \times 10^{-3}$ and 0.61 respectively.

\section{Conversion of Nylon waste powder into dibenzoyl derivative hexamethylene diamine (DBHMD)}

Conversion of nylon waste into HMD was carried out in a $250 \mathrm{ml}$ three necked round bottom flask fitted with extra long water condenser and Thermometer. The optimum parameters of depolymerization of Nylon - 66, were determined so as to get maximum yield of product. The general procedure adopted were consisting of carrying out thermal hydrolysis of fixed weight of Nylon-66 in three necked round bottom flask by using $5 \mathrm{~N}$, Hydrochloric acid on heating mantle for fixed time. After heating time at particular temperature, reaction mixture was cooled and then neutralized with strong solution of sodium hydroxide. Before neutralization reaction mixture was filtered over vacuum pump to get separate adipic acid and hexamethylene diamine. Hexamethylene diamine in the filtrate which was acidic was neutralized with sodium hydroxide. This neutralization was carried out in such way to make filtrate slightly alkaline. This was checked by litmus paper or $\mathrm{pH}$ meter. To this alkaline solution of hexamethylene diamine, AR grade benzoyl chloride was added in small installment with vigorous shaking on shaking machine. This process converts Hexamethylene diamine into dibenzoyl derivative of hexamethylene diamine (DBHMD) in the form of white crystal. Benzoyl chloride was added till the complete DBHMD is formed. It was then filtered on vacuum pump and then recrystalised with ethanol. The recrystalised DBHMD was dried in oven and then weighted accurately on digital balance. This data was recorded in the form of yield. The recrystalized product, DBHMD were dried in oven and stored in air tight bottle and IR spectra was recorded to confirm nature of functional group present. Similarly Pure hexamethylene diamine was converted into DBHMD and its IR spectra were also recorded, from two IR Spectra it was concluded both the samples were of DBHMD. 
Table 1: Conversion of Nylon waste powder to HMD and DBHMD: Variation of amount of nylon waste powder

\begin{tabular}{|c|c|c|c|c|}
\hline \multicolumn{3}{|c|}{$\begin{array}{l}\text { Time of reaction } \quad: 120 \mathrm{~min} \\
\text { Concentration of } \mathrm{HCl}: \quad 5 \mathrm{~N}\end{array}$} & \multirow{2}{*}{$\begin{array}{c}\begin{array}{c}\text { Temperature } \\
\text { Volume of } \mathrm{HCl}\end{array} \\
\begin{array}{c}\text { Amount of } \\
\text { Nylon waste } \\
\text { reacted/g }\end{array}\end{array}$} & \multirow{2}{*}{$\begin{array}{c}: \quad 80^{\circ} \mathrm{C} \\
: \quad 50 \mathrm{ml} \\
\begin{array}{c}\text { Amount of } \\
\text { unreacted nylon } \\
\text { waste/g }\end{array}\end{array}$} \\
\hline $\begin{array}{l}\text { Amount of } \\
\text { nylon waste } \\
\text { powder/g }\end{array}$ & DBHMD/g & HMD/g & & \\
\hline 1 & 0.96 & 0.3437 & 0.6706 & 0.3294 \\
\hline 2 & 1.926 & 0.6896 & 1.3453 & 0.6547 \\
\hline 3 & 3.101 & 1.1102 & 2.1661 & 0.8339 \\
\hline 4 & 2.919 & 1.0451 & 2.0390 & 1.9610 \\
\hline 5 & 2.815 & 1.0078 & 1.9663 & 3.0337 \\
\hline 6 & 2.301 & 0.8238 & 1.6073 & 4.3927 \\
\hline
\end{tabular}

Table 2: Conversion of Nylon waste powder to HMD and DBHMD: Variation of time of hydrolysis of nylon waste powder

$\begin{array}{lll}\text { Amount of Nylon Sample } & : & 3 \mathrm{~g} \\ \text { Temperature } & : & 80^{\circ} \mathrm{C} \\ \text { Concentration of } \mathrm{HCl} & : & 5 \mathrm{~N} \\ \text { Volume of } \mathrm{HCl} & : & 50 \mathrm{ml}\end{array}$

\begin{tabular}{lccc}
\hline Time/min. & DBHMD/g & HMD/g & Amount of unreacted nylon waste/g \\
\hline 30 & 0.589 & 0.2109 & 2.5886 \\
60 & 1.562 & 0.5592 & 1.9089 \\
90 & 1.901 & 0.6806 & 1.6721 \\
120 & 3.101 & 1.1102 & 0.8339 \\
150 & 2.802 & 1.0032 & 1.0428 \\
\hline
\end{tabular}

Table 3: Conversion of Nylon waste powder to HMD and DBHMD: Variation of temperature of hydrolysis of nylon waste powder

Amount of Nylon Sample

Heating time

Concentration of $\mathrm{HCl}$

Volume of $\mathrm{HCl}$
$3 \mathrm{~g}$

$120 \mathrm{~min}$

$5 \mathrm{~N}$

$50 \mathrm{ml}$

\begin{tabular}{lcccc}
\hline $\begin{array}{l}\text { Temperature/ } \\
{ }^{0} \mathbf{C}\end{array}$ & DBHMD/g & HMD/g & $\begin{array}{c}\text { Amount of } \\
\text { unreacted } \\
\text { nylon waste/g }\end{array}$ & $\begin{array}{c}\text { Amount of } \\
\text { Reacted nylon } \\
\text { waste /g }\end{array}$ \\
\hline 40 & 2.771 & 0.9921 & 1.0644 & 1.9356 \\
60 & 3.016 & 1.0798 & 0.8933 & 2.1067 \\
80 & 3.101 & 1.1102 & 0.8339 & 2.1661 \\
100 & 3.029 & 1.0845 & 0.8842 & 2.1158 \\
\hline
\end{tabular}


Table 4: Conversion of Nylon waste powder to HMD and DBHMD: Variation of Volume of $\mathrm{HCl}$ for hydrolysis of nylon waste powder

$\begin{array}{lll}\text { Amount of Nylon Sample } & : & 3 \mathrm{~g} \\ \text { Temperature } & : & 80^{\circ} \mathrm{C} \\ \text { Heating time } & : & 120 \mathrm{~min} \\ \text { Normality of } \mathrm{HCl} & : & 5 \mathrm{~N}\end{array}$

\begin{tabular}{lcccc}
\hline $\begin{array}{l}\text { Volume of } \\
\mathbf{H C l} / \mathbf{m l}\end{array}$ & DBHMD/g & HMD/g & $\begin{array}{c}\text { Amount of } \\
\text { reacted nylon } \\
\text { waste /g }\end{array}$ & $\begin{array}{c}\text { Amount of } \\
\text { unreacted nylon } \\
\text { waste/g }\end{array}$ \\
\hline 20 & 0.856 & 0.3065 & 0.5979 & 2.4021 \\
40 & 1.321 & 0.4730 & 0.9227 & 2.0773 \\
50 & 3.101 & 1.1102 & 2.1661 & 0.8339 \\
60 & 3.075 & 1.1009 & 2.1479 & 0.8521 \\
80 & 3.018 & 1.0805 & 2.1081 & 0.8919 \\
100 & 3.02 & 1.0812 & 2.1095 & 0.8905 \\
\hline
\end{tabular}

Table 5: Conversion of Nylon waste powder to HMD and DBHMD: Molecular weight determination of Nylon waste

\begin{tabular}{lccccc}
\hline $\begin{array}{l}\text { Concentration } \\
\%\end{array}$ & $\begin{array}{c}\text { Flow time of } \\
\text { Solution (t)/ sec. }\end{array}$ & $\begin{array}{c}\text { Flow time of } \\
\text { Solvent }\left(\mathrm{t}_{\mathrm{o}}\right) / \text { Sec. }\end{array}$ & $\begin{array}{c}\text { Relative } \\
\text { Viscosity }\end{array}$ & $\begin{array}{c}\text { Specific } \\
\text { Viscosity }\end{array}$ & $\begin{array}{c}\text { Reduced } \\
\text { Viscosity }\end{array}$ \\
\hline 1 & 426 & 170 & 2.5058 & 1.5058 & 1.5058 \\
0.50 & 269 & & 1.5823 & 0.5823 & 1.1646 \\
0.25 & 203 & & 1.1941 & 0.1941 & 0.7764 \\
0.125 & 178 & & 1.0471 & 0.0471 & 0.3768 \\
\hline
\end{tabular}

\section{RESULTS AND DISCUSSION}

The average molecular weight of Nylon -66 waste powder was determined by Ostwald's viscometer. Solvent which was used to prepare Solution of Nylon-66 was m-Cresol. By using the equation $[\eta]=K . M^{\alpha}$ molecular weight of Nylon -66 was determined. The values of constant $\mathrm{K}$ and $\alpha$ for m-cresol are $2.4 \times 10^{-3}$ and 0.61 respectively.

From Graph $\quad[\eta]=1.2$

$[\eta]=K \cdot M^{a}$

$1.2=\left(2.4 \times 10^{-3}\right) \cdot M^{0.61}$

$\log 1.2=\log \left(2.4 \times 10^{-3}\right)+0.61 . \log M$

$0.61 . \log \mathrm{M}=2.699$

$\log M=4.424$

$\mathrm{M}=\mathrm{A} \log 4.424$

$=26582.15$

The average molecular weight of used nylon waste powder is 26582. [Ref.Fig 1, Table 5]
The result obtained in table 1 and Figure 2 shows that the maximum conversion of nylon waste powder to HMD occurred at $3.0 \mathrm{~g}$ Nylon powder. The yield obtained is $73 \%$.Further increase in amount

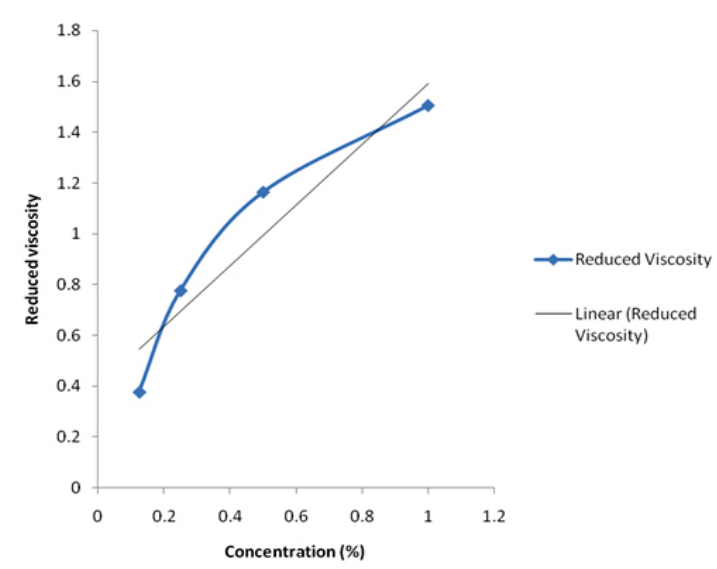

Fig. 1: Determination of Average Molecular weight of Nylon waste 


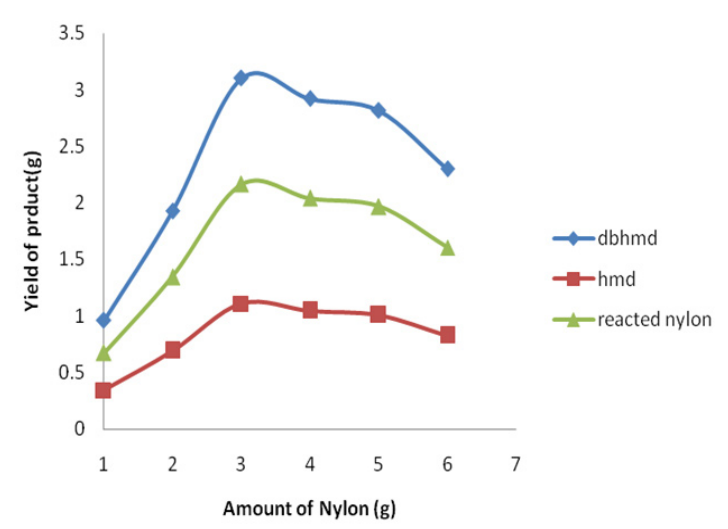

Fig. 2: Conversion of Nylon waste powder to HMD and DBHMD:Variation of amount of nylon waste powder

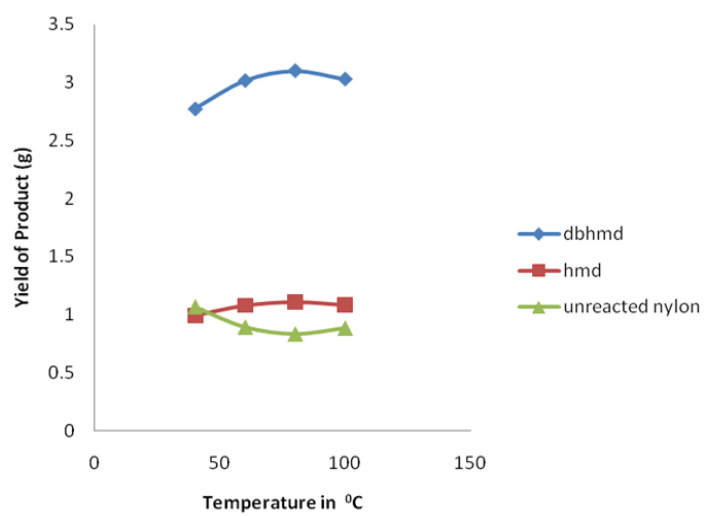

Fig.4: Conversion of Nylon waste powder to HMD and DBHMD: Variation of temperature of hydrolysis of nylon waste powder

of nylon waste, the \% conversion of nylon waste powder to HMD decreases and found to be $65 \%$ at $4.0 \mathrm{~g}$.Hence the maximum conversion obtained at $3.0 \mathrm{~g}$ of nylon waste powder.

The optimum amount of hydrochloric acid has been found to be $50 \mathrm{ml}$ having concentration of $5 \mathrm{~N}$. The variation is reported in Table 4 and figure 5.

The increase in time of hydrothermal depolymerisation increases the conversion of nylon waste into HMD. The maximum conversion took place

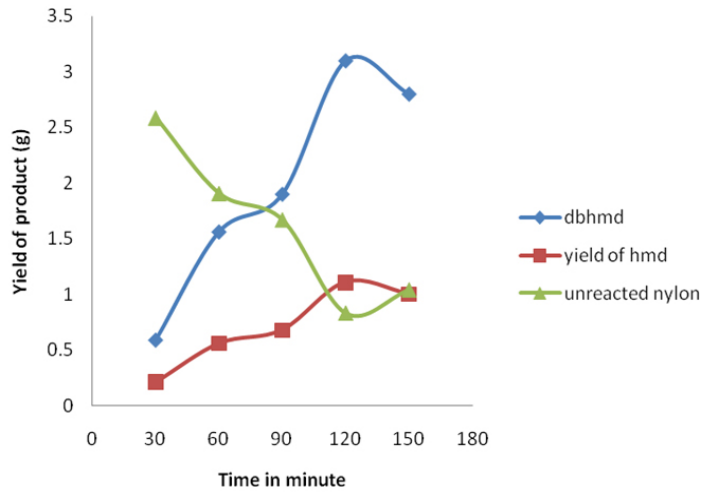

Fig. 3: Conversion of Nylon waste powder to HMD and DBHMD: Variation of time of hydrolysis of nylon waste powder

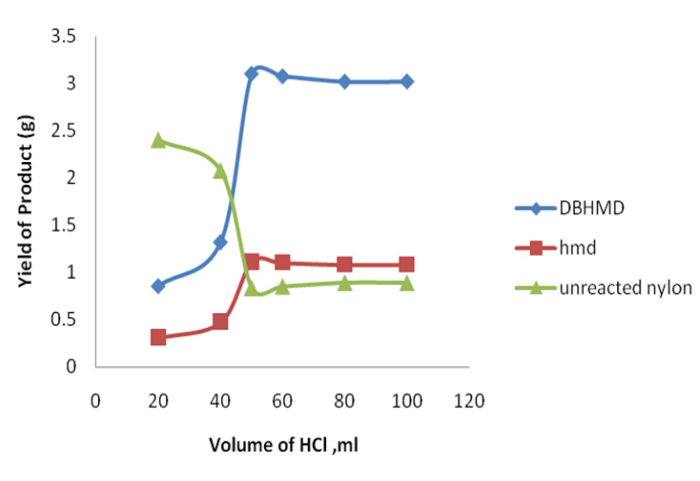

Fig. 5: Conversion of Nylon waste powder to HMD and DBHMD: Variation of Volume of $\mathrm{HCl}$ for hydrolysis of nylon waste powder

at 120 minutes.Further increase in the reflux time found to show negligible effect on the yield. [Ref. Table 2 and Fig. 3]

It is also observed that increase in temperature increases the conversion of nylon waste into HMD. The optimum temperature for the conversion is found to be $80^{\circ} \mathrm{C}$.[Ref.Table 3 and Fig.4].The HMD obtained after conversion was treated with benzoyl chloride to get dibenzoyl derivative of HMD.It was identified by recording its FTIR.[Ref.Fig. 6].It is observed that spectra of pure DBHMD is similar to spectra of authentic DBHMD. 


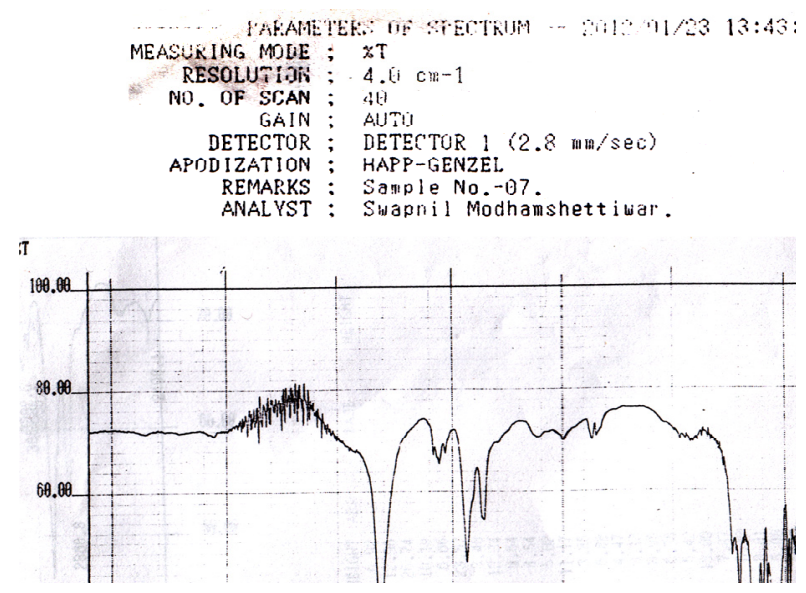

Fig 6: FTIR of DBHMD

\section{CONCLUSION}

A. The molecular weight of nylon waste powder determined by using solvent $\mathrm{m}$-cresol was found to be 26582 .

B. The maximum yield of DBHMD was obtained when $3 \mathrm{~g}$ of nylon waste powder undergoes hydrothermal depolymerisation.
C. The optimum reflux time recorded for conversion was 120 minutes.

D. The maximum temperature for the conversion is $80^{\circ} \mathrm{C}$.

E. The hydrothermal depolymerisation of nylon waste powder with $50 \mathrm{ml}, 5 \mathrm{~N}$ hydrochloric acid gives maximum yield of DBHMD.

\section{REFERENCES}

1. L.A.Dmitrieva, V. Nylon Fibre (1985).

2. R.N.Goel. Synthetic Fibre (1982).

3. E.Morf. Chemiefasern/Textilindustrire. 506: 30/82 (1980).

4. K.R.Wolff. Chemiefasern/Textilindustire. 500: 30/82 (1980).

5. R.D.Leaversuch. Modern Plastics 41: 68 (1991).

6. S.H. Ansari, A. Hasnat and A. Ahmad, Orient J. Chem., 28(2): 1015-1018 (2012)

7. Dupont., Patent No. 3,609,465. United state of America (1962).

8. I.Tomoko, S., Polymer degradation and stability. In 91: 1989-95 (2006).

9. B.Hmmez, E., Journal of macromolecular science, 1489-1505 (1998).

10. I.Mladenov, T., Polymer Society. 20: 341, USSR (1978).

11. A.M.Katlair and D.P. Fountain, Gorgia Tech., Synthetic wood from waste fibrous materials,U.S.Patent 5: 626,939 (1997). 